\title{
A Study on the teaching method of interior design major
}

\author{
Cong Pang ${ }^{1, a}$, Hui Zang ${ }^{2, b}$ \\ ${ }^{1}$ School of Dalian University, DaLian 116000, China ; \\ ${ }^{2}$ School of Dalian University of Technology, DaLian 116000, China. \\ a109860893@qq.com, b106772196@qq.com,
}

Key words: Interior design; Thematic teaching; Creative thinking

Abstract. With the rapid development of the national economy, people's living standards continue to improve, and people's requirements to indoor environmental quality are also getting higher and higher. Environmental art education in our country is divided into two directions: landscape design and interior design, and it is a new subject. There are still some problems in the mode of running school and teaching method. Teaching methods such as the lagging concept, facilities backward, slow renewal theory and so on. From the students' learning perspective, we found the defects such as emphasis on factual, blind plagiarism, putting together a design, not deep enough, the lack of details ect. In this paper, we put forward a new attempt to the teaching of interior design of environmental art, and hope to seek more advanced and more suitable for the development of education in the continuous research and research.

\section{I . The characteristics of interior design}

Interior design is a subject which involves many fields such as architecture, art, aesthetics, behavioral psychology and so on. Interior design is a science that studies the relationship between people and the establishment of physical and chemical medium. It has the knowledge structure of environmental psychology, art, architecture, art, architectural physics, technology structure, display art, project management, marketing, history and literature, law, design strategy and so on many contents, and it is an old and young subject, large diameter, wide range, large level. It is the core of human design, but also the process of engineering design, but also a real professional field for people and services.

As a professional direction in the field of environmental design, interior design focus on the design of interior space, and it's the continuation of architectural design. Therefore, in addition to the knowledge of architecture, the students of interior design should create the atmosphere, Lighting design and other aspects of comprehensive research and training in teaching can learn from the relevant theories of architecture, such as architectural history, environmental psychology, analysis of architectural master's creative thinking.

\section{The problems existing in the teaching at the present stage of interior design}

At present, the four-year undergraduate education of environmental design is generally based on the first-grade learning design basis, design performance, history theory and principle course, second and third year learning to design space-based professional design classes, including residential space, office space, Dining space, hotel space, etc .; fourth-grade learns the related laws, materials, construction and the graduate design such as integrated space design. In the teaching process, the general problems are as follow: 


\section{On the matter}

Architectural design course of indoor professional teacher will provide a general available to students, the limited space function of a certain type of design training (such as: residential space, office space, hotel space, commercial space, etc.). Teachers and students generally only paid attention to this kind of space in the form of case analysis and reference, are often surface mimic the effect of outstanding cases, select the reference case scheme which is suitable for their cultural background, conditions of use, function and scale requirements, and students don't do in-depth comparative study, have no design of master's intention, the process without the method of deep mining. Therefore, what students aturally learned is just the surface of a completed design results, not understanding the initial conditions of the original project research and analysis of favorable and unfavorable conditions of trade-offs and integration, how to design and improve the adverse conditions through the transformation. Students' design ability, resolving new problems or innovation do not been improved. And they will still feel too confusing to start if they met new challenge of the space designing.

\section{Blind plagiarism, do patchwork design.}

Imitation of excellent design is an effective way to quickly improve the design level, but the real purpose of imitation is to learn more excellent designer's way of thinking and creation process and method to solve the new problems and approaches, and the students really dig and comprehend the master creative concept is not very much, the students often only the blind copy design together do think little of. This phenomenon not only exists in the school students, even some of the designers who have been working for many years is also the case. Therefore, many of the works lack of its own design concept and style trend, the feeling is to put all sorts of things together mechanically, lack of integrity and innovation.

\section{Lacking basic theory research}

The basic theory such as environmental behavior, ergonomics and design methodology are the scholars and experts at home and abroad after years of valuable experience in practice research summed up the theoretical basis for the designer to design research. And students tend to ignore the relevant basis

Study on the basic theory, with the feeling of personal preferences and design, make the design only stay on the surface of the visual effects, a lack of research on the user, and then produce a lot of flashy without substance effect.

\section{Ignoring the details of the design}

Details of the decoration, and then produce the feeling of beauty, the owners are not only to meet their consumption function, but also hope that through the designer's design to get a high quality of life. While the students in the program design, often ignore the details of the space, to avoid some of the details of the deal, so that the design is just stuck in the conceptual stage, the lack of human. The research of material structure, manufacturing process and new technology is not enough, which restricts the students' creative thinking and creative ability.

\section{III. innovation measures to environmental design professional interior design courses}

The space design course occupies the dominant position in the teaching system. Through the four years' undergraduate professional learning, we can master the design methods of the common type space. However, a good and complete interior space design requires the novel design theme, suitable spatial scale, details of human nature, strong sense of space design and artistic atmosphere with an appeal, etc. and all aspects of the training points. Therefore, in the curriculum system should be added to a subject as the core form of teaching, according to the different levels of 
students to master the relevant professional knowledge to set up a number of thematic topics for students to conduct targeted research, such as master of environmental behavior psychology research, master case Analysis, spatial detail design, space environment, mood expression. In this way students can in-depth study of all aspects of design, and then flexibly used in the complete type of space design courses, then enhancing the overall level of design.

\section{Environmental behavior psychology research}

The traditional interior design courses, is usually designed for a certain type of function of building interior space. The advantage of this method is that can make students of a certain type of functional space for design, design to master the essentials of such space in the process of design in the understanding contained in the principle of universality the students, but also easy to cause defects on the title topic, to meet a new type of space, still feel strange and difficult to start. Although the interior space environment is difficult to completely determine human behavior, but as interior designers should be shaped by the environment, the people in accordance with the designer's intention to use and experience of environment, and then the corresponding behavior. Emphasize on people's behavior psychology in-depth study, so that students no matter what kind of space, are able to start from the needs of people to think, design, no doubt more universal and general. In view of teaching often occurs in the interior space of the behavior, such as residence, sports, quiet, noisy, privacy and publicity, and guide students to use professional knowledge to research, data collection and analysis data with graphics, tables and other methods to performance, to the analysis of the data as the interior space design. According to guide user behavior through the design, to meet the diverse needs of users, truly people-oriented.

\section{Master case analysis}

Selection of outstanding works of famous master of architectural design, interior design masters, through access to a large number of relevant literature, in-depth research and analysis of design style, excellent designers and their works selected the design idea and method, in the form of PPT in the classroom for students to explain the progress, can also be discussed on their own view. The master of outstanding case analysis, process of thinking and thinking about the master in design time, from the initial idea to the final completion of the program is how to step by step to complete, dig the logic relation among them, learn from the master thinking method and intention, to find suitable for their own method and design idea for me, the organic, innovative to use their own design rather than the surface of imitation and pieced together, only see things without the reasons and the process of their formation.

\section{Space detail design research}

The interior design in addition to separate the function of abroad should pay attention to the detail design decoration including material selection, configuration, processing of lighting effects, and soft decoration design, etc.. Due to the different observation distance, people pay more attention to the design of interior space of the building than the appearance of the building. Therefore, interior design and architectural design compared to pay more attention to the effects of material texture, different material interface or cohesion processing, lighting level and lighting with different material collocation and so on the details of the design, more emphasis on the effect of local micro processing. In order to improve students' ability of interior details, can put the scene with the students to the construction site for construction materials and production process of learning, let students feel the visual, tactile feel of different materials, different scales of space material specification requirements etc.. But also in the existing public buildings, a choice of materials, lighting, soft decoration distinctive design examples of research, analysis of its characteristics, material texture, texture, transition, head and structure processing, and graphics analysis, and mark 
the material scale. And further deepen the students' attention to design details and feelings, to improve the in-depth design capabilities.

\section{The expression of artistic conception and space emotion}

This is a higher level of the requirements of designers, but also the design of cultural literacy and aesthetic quality and other aspects of the comprehensive ability of the concentrated expression. Students usually need to pay more attention to the field of professional knowledge, training students divergent thinking, improve their comprehensive quality. In the teaching process can choose a poem or an article, require students to feel the authors want to express the mood, the use of professional knowledge, through the shape of the indoor space environment, create the artistic conception of poetry. Because everyone's understanding of literary works is not the same, the effect of the final presentation is also different, to fully express the imagination and creativity of each student.

During the teaching process of emotion expression of space, we can set several different abstract emotions, such as repression, worship, fear, solemnity, lively and so on.Students will deeply understand the influence of the abstract emotions on human psychology. They will learn the importance of space, lighting, color, material and other design elements for shaping of emotional space by making models, to create a space in line which is more adapt to the emotional characteristics of the form requirements.

\section{The conclusion}

In short, the improvement of the teaching methods, mainly to solve the problem of student learning in general. Through the above design theme settings, can cultivate students' research and data collection, summary and in-depth design, teamwork and language expression ability; to the market demand, strengthen practice teaching, thematic teaching, improve students' ability to analyze and solve problems; combined with the social demand for talents, fostering the the students' innovative thinking ability in the first place, and explore a new way of cultivating talents of high quality of the interior design.

\section{References}

[1] CHEN Yi. Design and decoration-The new thinking of [J]. Interior design and construction, 1997.5.

[2] XU Yuanyuan. "Thematic" interior design curriculum teaching research [D]. Nanjing Arts Institute, 2011.

[3] ZHOU Chao, Plant renovation-a full record of theme based teaching courses [J]. Interior Designers, 2008 (13) 